NBER WORKING PAPER SERIES

\title{
DOES MANDATORY DIVERSION TO DRUG TREATMENT ELIMINATE RACIAL DISPARITIES IN THE INCARCERATION OF DRUG OFFENDERS? AN EXAMINATION OF CALIFORNIA'S PROPOSITION 36
}

\author{
Nancy Nicosia \\ John M. MacDonald \\ Rosalie Liccardo Pacula \\ Working Paper 18518 \\ http://www.nber.org/papers/w18518 \\ NATIONAL BUREAU OF ECONOMIC RESEARCH \\ 1050 Massachusetts Avenue \\ Cambridge, MA 02138 \\ November 2012
}

Support for this project was provided by the National Institute on Drug Abuse (NIDA) (grant R01DA022719). The authors gratefully acknowledge comments from RAND's Drug Policy Research Center's brownbag seminar series, the NBER Summer Institute Economics of Crime Working Group, and discussants Christopher Carpenter and Patrick Bayer. The views expressed herein are those of the authors and do not necessarily reflect the views of of NIDA, the RAND Corporation, or the National Bureau of Economic Research.

NBER working papers are circulated for discussion and comment purposes. They have not been peerreviewed or been subject to the review by the NBER Board of Directors that accompanies official NBER publications.

(C) 2012 by Nancy Nicosia, John M. MacDonald, and Rosalie Liccardo Pacula. All rights reserved. Short sections of text, not to exceed two paragraphs, may be quoted without explicit permission provided that full credit, including $(\odot)$ notice, is given to the source. 
Does Mandatory Diversion to Drug Treatment Eliminate Racial Disparities in the Incarceration of Drug Offenders? An Examination of California's Proposition 36

Nancy Nicosia, John M. MacDonald, and Rosalie Liccardo Pacula

NBER Working Paper No. 18518

November 2012

JEL No. I18,K42

\begin{abstract}
Like other states, minorities are disproportionately represented in the California's state prison system, particularly for drug offenses. Unlike other states, California has had a policy of mandatory diversion to drug treatment for non-violent drug offenders since mid-2001 (Proposition 36). Using a rich dataset including current and prior criminal charges from 1995 through 2005 in California, we examine whether disparities in court dispositions to prison and drug treatment between White and Blacks male drug offenders are explained by observable case and criminal justice characteristics. We estimate the extent to which remaining observable disparities are affected by Proposition 36. We find that Black and White male drug offenders differ considerably on covariates, but by weighting on the inverse of a nonparametric estimate of the propensity score, we can compare Blacks to Whites that are on average equivalent on covariates. Unadjusted disparities in the likelihood of being sentenced to prison are substantially reduced by propensity score weighting. Proposition 36 reduces the likelihood of prison overall, but not differentially for Blacks. By contrast, racial disparity in diversion to drug treatment is not reduced by propensity score weighting. There is some evidence that Proposition 36 increased diversion for Blacks.
\end{abstract}

Nancy Nicosia

RAND

20 Park Plaza

Suite 920

Boston MA 02116

nicosia@rand.org

John M. MacDonald

Department of Criminology

University of Pennsylvania

483 McNeil Building

3718 Locust Walk

Philadelphia, PA 19104-6286

johnmm@sas.upenn.edu
Rosalie Liccardo Pacula

RAND Corporation

1776 Main Street

P.O. Box 2138

Santa Monica, CA 90407-2138

and NBER

pacula@rand.org 


\section{Introduction}

California has the largest state prison population in the country even after one normalizes for the state's residential population (Bureau of Justice Statistics, online). Shrinking state coffers have made the size of California's prison system a notable budgetary pressure, as the state spent $9.7 \%$ of its general fund on prisons in 2009 compared to only $6.6 \%$ on the University of California and California State University systems. ${ }^{1}$ California is not unique in its struggle to manage the problem of an exploding prison population. The United States' prison population nearly quadrupled between 1980 and $2004 .^{2}$ Research shows that convictions of drug offenders are one of the leading factors contributing to the growth in the prison population (Tonry, 1995; Blumstein and Beck, 2005; Mustard 2001; Mitchell, 2005; Raphael and Stoll, 2009). Raphael and Stoll (2009), for example, show that the proportion of drug offenses among new prison admissions grew from slightly over 10\% in 1984 to more than $30 \%$ in 1990, far outpacing growth in any other offense category. Since 1990, drug offenses have remained at least one-third of all new admissions (Raphael and Stoll, 2009). Similarly, Blumstein (2011a) notes that there has been a ten-fold increase in prison commitments for drug offenders nationally between 1980 and 2001 and that drug offenses alone contributed to a greater share of the increase in incarceration than any other felony offense type.

The rise in prison commitments for drug offenses has also contributed to a growing racial disparity in prison populations, as minorities are far more likely than Whites to be incarcerated for drug offenses (Tonry 1995; Mustard, 2001; Mitchell, 2005; Western, 2006). Research has examined a range of plausible explanations for racial disparities in prison commitments (Langan, 1985; Mustard, 2001), most noting shifts in drug sentencing policies that increase the probability

\footnotetext{
${ }^{1}$ http://2009-10.archives.ebudget.ca.gov/Enacted/agencies.html

2 (http://bjs.ojp.usdoj.gov/content/glance/tables/corr2tab.cfm)
} 
and duration of prison commitments (Tonry, 1995; Jacobs and Carmichael, 2001; Western, 2006; Keen and Jacobs, 2009). However, inadequate datasets and control variables coupled with generally weak identification strategies have left largely unaddressed the ultimate question of how much the observed racial disparities in prison commitments for drug offenses reflect disparate treatment of Blacks vis-à-vis Whites.

In this paper, we consider the issue of racial disparities in prison commitments for drug offenses, but with a more rigorous method for comparing the outcomes of Black and White arrestees. We make use of an impressively comprehensive administrative dataset in the state of California that contains information on important case and history criminal history characteristics for tens of thousands of drug offenders over a ten year period (1995-2005), a longer and more current period of study than previous work. We are able to use these administrative data to implement a nonparametric propensity score weighting scheme to align the joint distributions of White and Black males charged with drug offenses on all observables including prior criminal history, current case characteristics, age, and county of offense. Our dataset is sufficiently large to obtain substantial overlap between Blacks males and the weighted White comparison group, such that the two groups are on average equivalent on all observable characteristics.

Our analysis is further strengthened by a change in sentencing policy that was voted into law during the middle of our sample period. Proposition 36, which passed in November 2000 and was implemented in July of 2001, required the mandatory diversion of diversion of nonviolent drug offenders to treatment in lieu of prison thereby reducing judicial discretion judges with respect to sentencing. The law therefore creates a discontinuity in the likelihood of all offenders being sentenced to prison or diverted to drug treatment that can be exploited to 
examine changes in racial disparities. A major strength of this paper is, therefore, that we are able to examine how differences in prison commitments or drug treatment diversions shift for Blacks vis-à-vis Whites after the implementation of California's new sentencing law. This change has important implications beyond California, as other states are considering similar approaches to diverting drug offenders from prison and racial disparities in prison commitments remain a central issue in debates about the costs of America's drug control policies. The scale of the change in sentencing to prison and commitments to treatment for drug offenses is substantial after the Proposition 36 law went into place. To the best of our knowledge, this study provides the first empirical study of the effects of a systemic statewide reversal of a prison commitment policy on racial disparities for drug offenders. If Black arrestees are more likely than White arrestees to be sent to prison with similar case and criminal history characteristics, then a larger reduction in prison rates should be observed for Blacks relative to similarly-situated Whites after the implementation of Proposition 36. We use our matching design to estimate the impact of race on the likelihood of being committed to prison and drug treatment, and the discontinuity in the law caused by the implementation of Proposition 36 to assess whether there is change in racial disparities in these outcomes.

Unadjusted differences in prison commitments over the entire sample period show that Blacks are more than twice as likely as Whites to be sentenced to prison. This difference decreases substantially when Black males are compared to a weighted sample of Whites that are similar on observables largely due to inclusion of criminal history characteristics in the weighting. But Black males remain $17 \%$ more likely than similarly-situated Whites to be sentenced to prison. The implementation of Proposition 36 reduces the odds of going to prison for both Whites and Blacks, but the law does not differentially reduce commitments for Blacks 
more than similarly-situated Whites. The mean probability of being committed to prison for a Black male falls from a weighted likelihood of $6.8 \%$ to just $5.0 \%$ post Proposition 36. Similarly situated White males experience a similar reduction from $5.9 \%$ to $4.4 \%$.

The findings regarding sentences of drug treatment show a somewhat more perplexing story. Unadjusted differences indicate that Blacks are $43 \%$ less likely to be sentenced to drug treatment than Whites, and these differences do not materially change when comparing Blacks to similarly-situated Whites. The implementation of Proposition 36, however, does produce a $19 \%$ relative increase in the odds of diversion for Blacks compared to similarly-situated Whites. The results are due to a small decrease among Whites in addition to a slight increase among Blacks. Nonetheless, unlike our findings with respect to prison commitments, these results suggest that mandatory diversion does in fact modestly improve access to drug treatment for Blacks over similarly-situated Whites.

We begin with a discussion of California's Proposition 36 law which changed the policy on sentencing drug offenses and a review of the previous literature on racial disparities in criminal justice outcomes for drug offenses. Subsequent sections discuss the data and methods, the econometric results, and the policy implications from this study.

\section{California's Proposition 36}

In November 2000, voters in the state of California passed Proposition 36, which was implemented into law as the Substance Abuse and Crime Prevention Act, or "SACPA," in July 2001. Under Proposition 36, adult non-violent offenders charged with either simple drug possession, drug use, or transport of illicit drugs for personal use are automatically sentenced to 
probation with drug treatment instead of either probation without treatment or incarceration. ${ }^{3}$

Importantly, this diversion to probation with treatment also applies to offenders on probation and parole that would have normally been eligible for prison upon conviction. Information on California's Department of Alcohol and Drug Program's webpage, the agency responsible for funding Proposition 36, states that the intent of the law as follows: "(1) Preserve jail and prison cells for serious and violent offenders; (2) enhance public safety by reducing drug-related crime; and (3) improve public health by reducing drug abuse through proven and effective treatment strategies."

It is important to understand that while Proposition 36 was the first large initiative of its kind and poured $\$ 120$ million of state funds each year to pay for criminal justice supervision and drug treatment, it was not the first initiative in California to divert non-violent drug offenders to treatment instead of prison. Adult and juvenile drug courts both existed within the state in selective counties beginning in the early 1990s. According to California's Drug Court webpage, the very first adult drug court in existence in California was in Alameda County in $1991^{5}$, although some scholars state it started in 1993 (Drug Court Partnership Final Report, 2002). Juvenile courts emerged in the mid-1990s in a few select counties. It was not until 1998, however, that state-wide funding and support of developing drug courts across the state became available with the passage of a policy known the Drug Court Partnership Act (DCPA). As is often the case, funding lagged behind the policy implementation date, but in 1999 the DCPA became fully “operational," allocating \$4 million in funding for the development and implementation of drug courts in the largest 18 counties in May 1999 and another 16 counties in

\footnotetext{
${ }^{3}$ On May 27, 2005, California's Supreme Court ruled that driving under the influence of an illicit drug would not be an eligible offense and offenders could not be sent to treatment in lieu of prison.

4 http://www.adp.ca.gov/sacpa/prop36.shtml, accessed 12/16/2011.

${ }^{5}$ http://www.adp.ca.gov/DrugCourts/overview.shtml
} 
July. ${ }^{6}$ The funding supported the development of both judicial resources in support of drug courts and, to a lesser degree, expansion of drug treatment (Drug Court Partnership Final Report, 2002).

As the DCPA was restricted in its support only of adult drug courts, a second initiative called the Comprehensive Drug Court Implementation Act of 1999 (CDCI) was passed in 1999 with the purpose of expanding support for adult drug courts as well as the development of juvenile drug courts, dependency drug courts, and family drug courts. Financial support was provided through a grant making process, but counties had to formally apply for funding. Beginning in December 2000, an additional \$9.5 million was awarded to 47 counties in the development and implementation of adult, juvenile and alternative forms of drug courts (California Department of Alcohol and Drug Programs, 2004).

Although it is clear that drug courts existed prior to 1999 , the real funding by the state to support greater access across multiple counties did not begin until the passage of the DCPA and CDCI. Together, the funding for both these initiatives was substantial for the time period (e.g., \$18 M in 2000-2001 across both programs), particularly relative to existing state spending on drug treatment. Statewide drug courts, however, still involved the discretion of the prosecutor and the judge in determining who would be eligible and who would not. Moreover, it was the judge who determined whether drug treatment, counseling, or drug education could "work", whether the offender was compliant with the program they were assigned to, and whether the offender could stay in the community instead of being committed to prison. Thus, there was an opportunity for discretion (and perhaps bias) to influence rates of imprisonment and access to treatment under the selective drug court system in California.

\footnotetext{
${ }^{6}$ There are 58 counties in the state of California, so the funding from this initiative supported courts in just over half of the counties.
} 
When Proposition 36 passed in November 2000 as a ballot initiative and implemented as "SACPA" in July 2001, it represented a very real and substantial change to the landscape for drug offenders, in part because of the significant dollar resources allocated to the program ( $\$ 120$ million each year), which dwarfed previous efforts. Proposition 36 expanded eligibility for treatment in lieu of prison to all non-violent drug offenders caught in simple possession (not just those that a judge deemed "possible to rehabilitate") by including second-time offenders as well as first-time offenders, and by applying uniformly in all counties rather than just those with a drug court system.

The impact of the DCPA, CDCI-funded drug courts and Proposition 36 on treatment admissions in California is clear (see Figure I). ${ }^{7}$ Following the DCPA and the CDCI in 1998 and 1999, treatment admissions from the criminal justice system increased substantially. The most dramatic increase occurs in 2001 with the influx of Proposition 36 dollars. Clearly, the two programs were effective in that they increased the use of drug treatment programs among those involved in the criminal justice system. Perhaps most importantly for our study, the programs appear to have increased admissions similarly across Blacks and Whites.

$<$ Figure I about here>

Part of Proposition 36's goal was to reduce the use of incarceration by providing treatment in the community. Trends in commitments to prison among drug offenders in California suggest that commitments started declining most rapidly with the implementation of Proposition 36 with Whites and Blacks both experiencing fewer commitments.

$<$ Figure II about here>

\footnotetext{
${ }^{7}$ The 3-month moving averages are weighted .5 for the current month and .25 for the previous and subsequent months.
} 


\section{Prior Literature on Racial Disparities for Drug Offenses}

There is substantial evidence that racial disparities in prison commitments are greatest among drug offenders (Blumstein and Beck, 2005; Mustard, 2001; Mitchell, 2005; Raphael and Stoll, 2009). What accounts for this fact is unclear. Minorities do experience higher arrest rates than Whites for drug violations, which may be due in part to a focus on outdoor drug markets and specific forms of drugs like crack cocaine and the geographic concentration of police resources in minority areas (Riley, 1997; Reuter et al., 2000; Beckett et al., 2006; Ramchand et al., 2006). Blumstein (1993) hypothesized that because Blacks are more likely than Whites to live in inner-city neighborhoods with a greater police presence and more likely to buy and use in open-air drug markets, they are more likely to be arrested for drug offenses. As a result, a greater apprehension of Blacks compared to Whites is driven by differences in the distribution of police resources and private spaces for users. Tonry (1994) offers similar arguments and adds to these two arguments a third: law enforcement agencies show their productivity through the number of arrests achieved, and it is easier to arrest people who are violating laws in the open in minority neighborhoods than to search for violators in private spaces in middle-class White neighborhoods. Thus, resources are focused on running stings and undercover buys in minority neighborhoods where it is easier to catch offenders.

Empirical evidence supporting these hypotheses comes from both qualitative and quantitative analyses conducted at the national and city level (Beckett et al., 2006; Ramchand et al., 2006; Reuter et al., 2000). Reuter et al. (2000), for example, provide a careful examination of marijuana possession arrests within the state of Maryland, which experienced an enormous increase in racial disparities over a relatively short period of time. More than half of these arrests resulted from direct observation by police officers and another $35 \%$ from 
regular traffic stops. Importantly, these arrests were also highly concentrated in particular heavily minority neighborhoods. These were the same neighborhoods generating the vast majority of other arrests as well, suggesting that at least some of the racial disparity observed in marijuana possession arrests could be attributed to law enforcement policies concentrating resources in neighborhoods with a large share of minorities. Beckett et al. (2006) similarly found that the geographic concentration of law enforcement resources in minority areas is a major contributor to racial disparities in drug delivering charges in Seattle. Using data from a variety of sources, they found that both the focus on crack cocaine and minority neighborhoods explains most of the racial disparity in arrest rates for drug delivering. While they find that the focus of law enforcement resources on outdoor air markets exacerbates the disparity in arrest rates, it is not a major driver as Blacks are also over-represented in busts from indoor exchanges. Finally, Ramchand et al. (2006) used self-reported information on marijuana purchases from the 2002 National Survey on Drug Use and Health to estimate the likelihood of buying drugs outdoors, from a stranger and away from one's home. After controlling for demographic variables, current and past drug use, and general drug market covariates, they find that Blacks are nearly twice as likely to report buying marijuana outdoors than Whites and nearly three times more likely to buy from a stranger.

There is also ample empirical research supporting the hypothesis that tough sentencing regimes, particularly increased penalties for drug violations, are also to blame for the large increase in the number of Blacks sent to prison relative to Whites (Jacobs and Carmichael, 2001; Bushway and Piehl, 2001; Western, 2006). Tonry (1995) presents evidence showing that the percent of violent crime committed by Blacks between 1976 and 1992 remained relatively stable over the period while the share of their prison commitments rose sharply. The primary factors 
driving this change were policies toward drug offenses. In 1980, only $22 \%$ of new admissions to prison and $25 \%$ of resident prisoners in federal prisons were sentenced for a drug offense. By 1992, $42 \%$ of new admissions to prisons were for drug offenses and $58 \%$ of the total resident prison populations were individuals committed primarily for drug offenses. Thus, there was a compositional shift in the types of crimes people were being committed to prisons for, and this shift disproportionately impacted Blacks. ${ }^{8}$

One of the more rigorous studies on racial disparities, conducted by Mustard (2001), found that $55 \%$ of the Black-White difference in prison sentences for federal offenders (for various crimes) was due to departures from federal guidelines. For drug-trafficking crimes, Mustard found that $66 \%$ of the racial difference comes from departures from federal guidelines, with Blacks being less likely than Whites to receive downward departures of no prison time. The disparities also appear to be greatest for Black men and those in the lowest income bracket. ${ }^{9}$ Evidence of racial disparities in prosecutors' decisions to bargain down charges (Spohn and Fornango, 2009) and judges' deviations from sentencing guidelines (Engen et al., 2003;

Bushway and Piehl; 2001) have also been identified as contributors to racial disparities in the use of prison.

The current level of racial disparity in prison commitments is not fully explained by the shift in the types of crimes resulting in a prison sentence (and the over-representation of Blacks in the participation of those crimes). Research on racial disparities in court dispositions also suggests that the seriousness of the offender's criminal record matters (Kramer and Steffensmeier, 1993). A number of studies using individual-level data show that most of the

\footnotetext{
${ }^{8}$ Tonry (1995) also shows that the number of drug arrests among Blacks more than doubled between 1985 and 1989 , when the penalties for drug crimes were steadily made harsher, whereas White drug arrests rose by only $27 \%$.

${ }^{9}$ What this study doesn't address is whether the departures are more likely to be awarded due to defendant cooperation, as is often the case in federal cases.
} 
differences in the court dispositions can largely be explained by a combination of information on the severity of offenses and prior criminal records (Klein et al., 1990; Steffensmeier and Demuth, 2000; Langan 2001; Harris, Steffensmeier, Ulmer and Davis, 2009). Thus, inclusion of both current case characteristics and prior criminal history would be important for properly identifying a true race effect. Controlling for case characteristics can be tricky as these factors also directly influence the recommended sentences prescribed in state penal codes (Bushway and Piehl, 2001). Moreover, the functional form that circumstances of arrest and prior criminal records have in differentiating outcomes by race is unclear. This means that standard regression models that examine the effect of race on court dispositions and include covariates are likely to be misspecified. This is akin to the common problem of identification in non-experimental evaluations (Smith and Todd, 2005) and one that was noted as a general problem in racial disparity research on the criminal justice system by a National Academy of Sciences (Klepper, Nagin, and Tierney, 1983).

In addition to these technical issues that exist when trying to properly estimate the effect of race on differences in court outcomes, there is the additional problem of the non-equivalence of race on key covariates. Non-equivalence of race refers to the notion that important background differences exist between Whites and Blacks that are confounded with race. For example, Blacks are more likely than Whites to have prior convictions and commit a concurrent offense (e.g., possession of illegal guns or assault), which immediately changes the prescribed sentence and/or the eligibility for a reduced non-prison sentence, especially in states with mandatory-minimum sentences for weapons-related offenses. Similarly, Blacks are more likely to live in urban areas with high crime and poverty rates and more overall policing (Blumstein and Wallman, 2000). Without adequately taking into account the circumstances of the arrest 
and/or the prior convictions, one may mistakenly attribute to race issues that are more common among a racial group for reasons related to structural disadvantages and not necessarily the race of the offender. The structural disadvantages in high poverty-crime areas that are more likely to receive intensive police resources may be the drivers of racial disparities in drug arrests and prison commitments more than individual biases on the part of prosecutors and judges.

To summarize, identifying of true racial disparity in prison commitments or diversion to drug treatment is complicated by the fact that the differences between circumstances of current cases and criminal backgrounds for Blacks and Whites are substantial, the functional form that determine how these attributes affect sentencing outcomes is uncertain, and prior datasets have suffered from incomplete information on cases and limited time periods. Prior studies assessing the impact of racial disparities in court dispositions may be biased therefore due to omitted factors that are significantly confounded with race. In the current study, we have the advantage of a rich administrative dataset that covers multiple years in time, an identification strategy that creates distinct comparability for Black and White drug arrestees, and an exogenous shift in the sentencing law that creates a discontinuity in the probability of a prison sentence for drug offenses. Moreover, this study fills an important void in the literature by considering the importance of racial disparity in court dispositions to drug treatment, which is supposed to be the primary sentencing alternative to incarceration for drug offenses. While Blacks represent $33 \%$ of all drug-related arrests, they only represent $22 \%$ of all criminal justice referrals to treatment (SAMHSA, 2005). We are not aware of any study that has evaluated why this is the case.

\section{Methods}

\subsection{Data}


The data for our study relies on the full criminal record, including history of prior criminal offenses, for a random sample of 200,000 individuals who had a drug-related offense on their record between the years 1980-2008. This California's Automated Criminal History System (ACHS) provides the complete criminal justice and criminal court history of each arrest, including current charges, court filings, and resulting court dispositions. Information on individual race/ethnicity, age at arrest, gender, and the exact date for each criminal justice "event" (arrest, complaint, plea, conviction, sentencing and referrals) and location (county code) were abstracted, from which we created an event-based dataset. ${ }^{10}$ From these data, we extracted arrests for all male arrestees that were either Black or White, representing approximately 55 percent of the total sample. ${ }^{11}$ We focus on Black-White comparisons because they present the starkest contrast between the probabilities of prison and diversion to drug treatment in California and because they are central to the disparity-policy discussion. The data contain misdemeanors and felony drug offenses, which are useful for an analysis of drug courts and diversion under Proposition 36. It is important to underscore that these data provide the most complete automated criminal history system to be used in a recent racial disparity in criminal justice study.

The offense categorizations (CJIS codes) are unique to the health and safety, penal, vehicle, and other California codes. From these codes we created categories of offense types and the eligibility of specific offenses for drug treatment diversion under Proposition 36 guidelines. ${ }^{12}$ There are 611 different offenses that qualify under California's health and safety codes as "drugrelated" of which 106 are eligible for diversion to drug treatment under Proposition 36. Drug

\footnotetext{
${ }^{10}$ Although the primary use for the RAPP data are criminal justice processing, they have been used in previous research to examine issues relating to criminal justice and diversion to treatment (e.g., Wintemute et al. 2001; Prendergrast et al., 2004; Ettner et al., 2005).

${ }^{11}$ The single largest other ethnic group to compare comprised of Hispanic males. The Hispanic-White disparities in outcomes were less pronounced in the unadjusted data.

${ }^{12}$ These variables were created from linking over 4,000 separate penal code offenses to summary forms provided by California Department of Justice (Cal DOJ) that distinguish between misdemeanor and felony offenses and general categorizations.
} 
offenses ranged from misdemeanor offenses of being under the influence of illicit drugs (e.g., Under Influence of Hashish) to felony offenses of possession and transportation/sales of illicit drugs (e.g., Possess Hashish; Possess Hashish for Sale).

To generate a more comparable sample with complete criminal histories, we focused on Black and White male offenders whose criminal activity was confined to California. We further restricted the sample to those arrests in California that occurred during the period from 1995 to 2005. ${ }^{13}$ This restriction ensured that the only major sentencing change influencing the results was the implementation of Proposition 36 in 2001. ${ }^{14}$ We transformed these criminal history records into an arrest-level analytic file with variables that measure the severity of offenses in the current arrest and all criminal involvement prior to the current arrest. ${ }^{15}$ The final analytic database consisted of 96,507 felony and misdemeanor drug-related arrests. ${ }^{16}$

Outcomes. We focused on individual dispositions for a drug arrest that resulted in either a prison commitment or diversion to drug treatment. We chose these two outcomes because they speak directly to the issues of racial disparities in the use of prison or diversion to treatment for drug-related offenders. Other court dispositions that were also observed in the data include jail, probation, prosecutor release, and court dismissal. ${ }^{17}$

\footnotetext{
${ }^{13}$ Cal DOJ provided the study investigators with the list of Prop 36 eligible offenses that linked to health and safety code violations.

${ }^{14}$ In 1994, California voters passed the Three Strikes Law.

${ }^{15}$ Because our sample of arrests is drawn from a random sample of criminal histories, the same individual can appear multiple times in our sample of drug arrests. What this also means is that these individuals with repeat arrests are accumulating longer and potentially more severe criminal history records, which may affect the likelihood of diversion as well as prison dispositions especially over time.

${ }^{16}$ An additional $12 \%(n=13,077)$ of cases were removed because of a coding error in the data series, which made it impossible to tell whether the arrests occurred before or after the court dispositions. Including these cases in the analysis, however, did not materially change the results reported in this study. In fact, the effective sample size for our matched sample of Whites in our subsequent analysis was larger $(n=8,517)$ when we excluded this coding error cases than when we included them $(n=8,055)$.

${ }^{17}$ The analysis focuses only on the alternatives between prison and drug treatment, which are the two dispositions most directly affected by the legislation and most relevant to the literature.
} 
Case characteristics and criminal history. For each arrest, we compiled the characteristics of that arrest. To help summarize the offense information we merged information on crime severity indices and offense categorizations from Cal DOJ records systems. To measure individual case-characteristics we include an indicator for whether the current drugrelated offense is eligible for Proposition 36 in 2001 (yes-no). We include a measure of the number of offenses on the current arrest charge; type of offenses (misdemeanor vs. felony; violent, drug, property, other); dummy indicators for whether a weapon or sexual offense was included in the current arrest; and a measure of the maximum and median severity ${ }^{18}$ for the criminal offenses comprised in each arrest. To measure an arrestee's criminal history we include a number of variables including: number of prior arrest offenses; number of prior felony arrests; number of prior drug felony arrests; number of prior drug misdemeanor arrests; number of prior violent felony arrests; number of prior violent misdemeanor arrests; number of prior convictions; prior weapon offense (yes-no); prior prison (yes-no); prior probation (yes-no); prior parole (yes-no); arrest record as a juvenile (yes-no); and prior warrants (yes-no).

Demographics. Our primary independent variable of interest is whether an arrestee was Black or White, which is self-reported by the individual and checked against documentation (e.g., driver's license) and existing criminal records. Age (date of birth) is also checked against available documentation. Race/ethnicity and other characteristics may be assessed or confirmed at each arrest. ${ }^{19}$

\footnotetext{
${ }^{18}$ The severity index is a measure used by Cal DOJ to describe the severity of a given offense with 1 equaling murder and 72 representing misdemeanor offenses.

${ }^{19}$ The Cal DOJ has processes to ensure data quality. To avoid introducing error, a change relative to existing records is not made without further confirmation. In addition, if a system user reports that an event (e.g., disposition) is missing or inaccurate, the Cal DOJ attempts to fill in the missing information or confirm the contested information through the original agency.
} 
Time and Location Fixed effects. We also include month and year fixed effects to control for seasonality and secular trends in offending, and county fixed effects to account for time-invariant county-specific unobservable factors.

\subsection{Empirical Model}

Our objective is to assess Black-White disparities in drug-related court dispositions to prison or drug treatment for arrestees in California. We rely on a potential outcomes framework (see Rubin, 1974; Angrist, Imbens, and Rubin, 1996; Morgan and Winship, 2007; Imbens and Rubin, 2008) as our method for identifying the race effect on these criminal justice outcomes, or the difference between the expected outcomes (denoted by y) observed for individuals who are Black (denoted by $t=1$ ) and the outcomes that would have been observed had those same individuals been White ${ }^{20}$ (denoted by $t=0$ ) or formally as:

$$
\mathrm{E}\left[\mathrm{y}_{1} \mid \mathrm{t}=1\right]-\mathrm{E}\left[\mathrm{y}_{0} \mid \mathrm{t}=0\right]
$$

We cannot observe this potential outcome because individuals cannot be assigned a different race, but we can estimate it by comparing differences in the average probability of outcomes for a set of Black arrestees (denoted by $y_{1}$ ) to Whites arrestees with similar observable characteristics (denoted by $y_{0}$ ) or formally as:

$$
E\left[y_{1} \mid t=1\right]-E\left[y_{0} \mid t=1\right]=E\left[y_{1}-y_{0} \mid t=1\right]
$$

A propensity score approach for identifying the race effect under this potential outcomes model requires that we estimate the probability that an individual with a set of observed

\footnotetext{
${ }^{20}$ Some have argued that race can't be construed as a causal variable because it cannot be directly manipulated. We adopt a less conservative framework along the lines cited by the National Academy of Sciences and argue that after controlling for all confounding observables that we provide "a framework in which causal statements about nonmanipulable variables such as race are possible" (National Research Council, 2004; p. 79). See related arguments set forth by Paternoster and Brame (2008) in their study of racial disparity in the use of the death penalty in Maryland.
} 
characteristics ( $\mathrm{x}$ ) is Black. We predict the probability that an individual is Black based on his age at arrest, case characteristics and criminal history previously described, (arrest) county, and year and month of arrest. In all we have 34 individual case and criminal history covariates and over 250 fixed effects (e.g. crime severity, age, month, and year).

To estimate this probability we use a nonparametric propensity score model that includes non-linear relationships between covariates (i.e. 3-way interaction terms for all variables) and allows for high correlation in observables (McCaffrey, Ridgeway, and Morral, 2004). We use the boosted logistic regression method described in McCaffrey et al. (2004) to compute the propensity scores. This method estimates the propensity scores from a nonparametric logistic regression model that includes a penalty term to constrain any undue influence by coefficients in fitting the model (Tibshirani, 1995). We will denote the propensity score for respondent $i$ as $p_{i}=P\left(t=1 \mid \mathbf{x}_{i}\right)$. The associated penalized log-likelihood function is specified by the following form:

$$
\ell(\alpha)=\sum_{i=1}^{n} t_{i} \alpha^{\prime} \mathrm{f}\left(\mathrm{xi}_{\mathrm{i}}\right)-\log \left(1+\mathrm{e}^{\alpha^{\prime} \mathrm{f}(\mathrm{xi})}\right)-\lambda \sum_{j=1}^{J} \alpha_{j}
$$

where $f(x)$ is a set of basis functions consisting of all piecewise constants of the case characteristics (e.g. individual criminal histories, age, time, and county-fixed effects) and their interactions (up to three-way interactions). The collection of basis functions helps flatten the estimated propensity scores at extreme values of $x$, thereby minimizing the chance of a propensity score near 0 and 1 that can produce high variability in the weights (which can occur with standard linear basis functions of $\mathrm{x}$ ). The summation on the far right represents a penalty term that reduces the log-likelihood when the parameters $\alpha_{j}$ are large in absolute value. For a fixed value of $\lambda$, the estimated $\alpha$ can have many coefficients equal to 0 , and then 
only the best predictors of the propensity score $t$ will be nonzero in value. We can also include a number of highly-correlated predictors of the propensity score, as the term acts as a coefficient shrinkage and variable selection penalty, which will include only the information in the covariates that produces the best out-of-sample prediction (Ridgeway and MacDonald, 2009). We estimate the propensity scores and then compare arrestees that are Black $(\mathrm{t}=1)$ to White arrestees who are weighted by $w_{i}=p_{i} /\left(1-p_{i}\right)$.

This weighting scheme aligns the joint distributions of White arrestees' characteristics with those of Black arrestees. This has the benefit of maximizing overlap in the distributions of Whites and Blacks on covariates. White arrestees with features, $\mathbf{x}$, that are quite different from the characteristics of Blacks, such as differences in current case severity, prior criminal history record, county of residence, will have propensity scores near 0 and therefore will receive small weights. Whites with large propensity scores, on the other hand, have features that are very similar to Blacks and so will receive larger weights (Hirano and Imbens, 2001; Wooldridge, 2002; Hirano, Imbens, and Ridder, 2003).

Some advantages to this propensity score weighting approach over tradition regressionbased adjustments include the following: (1) we adjust only for covariate differences between Blacks and Whites and remove all observable variable biases associated with differences (Rosenbaum and Rubin, 1983); (2) we do not have to rely on any assumptions about the functional form between control covariates and the outcome measures (Ho et al., 2007); (3) as long as our propensity estimated score is monotonically related to the true propensity score we obtain an unbiased estimate of the treatment effect (Heckman and Todd, 2009); (4) by obtaining comparable cases on covariates before analysis we guard against the common problem with regression where large imbalances in covariates lead to model extrapolation (Stuart, 2010); (5) 
weighting by the inverse of a nonparametric estimate of the propensity score allows us to obtain an efficient estimate of the average Black-White disparity in outcomes (Hirano, Imbens, and Ridder, 2003); and (6) by relying on a nonparametric boosted logistic regression algorithm that finds substantial overlap between Blacks and Whites in the estimated propensity score we avoid the potential problem of bias that can occur with inverse probability weighting methods (Busso, Dinardo, and McCrary, 2011). The nonparametric boosted logistic regression model we employ is also superior to a parametric logistic regression model for obtaining balance on background covariates when there are interactions and non-linear relationships between covariates and the groups being compared (McCaffrey et al., 2004; Lee et al., 2009). And, within the general class of standard machine learning algorithms boosting has been shown in propensity score estimation to have "substantially better bias reduction" (Lee et al., 2009). ${ }^{21}$

Through the application of propensity score weights the average of each Black arrestee's outcome becomes the only observable feature that could differ from White arrestees. To assure that comparable cases are constructed, equalizing Black arrestees to match White arrestees on observable features, we estimate the propensity scores separately for the period before (1995-June 2001) and after (July 2001-2005) the implementation of Proposition 36. We then estimated the effect of race on the probability of prison (and drug treatment) dispositions according to a weighted logistic regression model with $t$ ("race") as the only covariate.

$$
\log \left(\frac{\mathrm{pi}}{1-\mathrm{pi}}\right)=\beta_{\mathrm{o}}+\beta_{1} * t_{\mathrm{i}}
$$

\footnotetext{
${ }^{21}$ By standard alternatives we refer to parametric logistic regression and different machine learning algorithms like classify analysis regression trees (CART), pruned CART, ensemble methods of bagged CART, and random forests (Lee et al. 2009).
} 
The standard error of $\beta_{1}$, the coefficient for $t$, is estimated with a sandwich estimator to account for the weights (Huber, 1967).

We integrate the discontinuity caused by the passage of Proposition 36 on drug-related outcomes into our propensity score model using a difference-in-difference estimator. We assume that the shift in the overall probability of prison and drug treatment dispositions around the implementation of Proposition 36 is exogenous to the race of the arrestees. Thus, by incorporating the before-after difference in outcomes for Blacks relative to Whites, we capture whether the law produced any net shifts in racial disparities.

$$
\log \left(\frac{\mathrm{pi}}{1-\mathrm{pi}}\right)=\beta_{0}+\beta_{1} * t_{\mathrm{i}}+\beta_{2} * P 36_{i}+\beta_{3} *(t * P 36)
$$

In equation 5 we include a parameter $\left(\beta_{1}\right)$ measuring overall effect of race $(t)$ and the passage of Proposition $36\left(\beta_{2}\right)$. By also including the interaction between the race and Proposition 36, we capture the difference-in-differences estimate, or the Black-White effect (pre-post) of this law on dispositions. If the new regime shifted the treatment differentially for Blacks, then $\beta_{3}$ will measure this, thus estimating whether the overall effect of Proposition 36 was more or less beneficial for Blacks relative to Whites.

\section{Results}

Table I presents the results from comparisons of Blacks to Whites for all the covariates before and after weighting on their respective propensity scores for the pre- and post-Proposition 36 time periods. Prior to weighting, there are a number of substantial differences in current arrest characteristics and in criminal history between Blacks and Whites in our sample even though they have all been arrested for a drug-related offense. Blacks are more likely than Whites to have a felony drug offense, more severe offense score (arrest severity minimum and 
median), more extensive prior criminal history for all forms of felonies and misdemeanors, and higher prevalence of current warrants and are also more likely to have had a prior prison sentence and at least one juvenile arrest.

After weighting on the propensity score, we find a suitable set of White comparison cases that minimize these Black-White differences on all the current and prior case characteristics. We are also able to minimize the average differences between Blacks and Whites in terms of counties, age groups, and time trends by weighting on the propensity score. ${ }^{22}$ The effective sample size for White comparison cases shrinks from a total sample of 70,889 to 8,517 cases, demonstrating that a substantial share of Whites in our original sample were not directly comparable to Blacks. ${ }^{23}$ Despite this substantial loss of sample, we have sufficient numbers to remove the influence of average case characteristics from the estimated average race effect on outcomes. $^{24}$ This is an important feature, as scholars have noted the limitations of traditional regression methods in estimating racial disparities when offense severity and criminal histories are confounded with race (see Klein, Berk, and Hickman, 2005). The important point to emphasize is that the propensity score comparisons estimated minimized the differences on all observables prior to estimating any outcomes differences, such that the standardized mean

\footnotetext{
${ }^{22}$ Blacks, for example, were more likely to come from urban counties like Alameda and Los Angeles. After weighting on the propensity scores, however, cases are balanced on county-level variation. The results are available from the authors.

${ }^{23}$ The effective sample size is calculated by ESS $=\frac{\left(\sum_{i \in \text { comparison }} w_{i}\right.}{\sum_{i \in \text { comparison }} w_{i}^{2}}$

${ }^{24}$ Kang and Schafer (2007) argue that using propensity score weights can be unstable, but the discussion in Ridgeway and McCaffrey (2007) demonstrates that this is largely due to the use of parametric logistic regression models for estimating the propensity score rather than a deficiency in the method itself. Our use of the boosted nonparametric logistic regression model to estimate the propensity score avoids these issues. Our single largest weight $(=23)$ is equivalent to a propensity score of $0.959(\mathrm{w}=\mathrm{p} / 1-\mathrm{p})$, bounded some distance from 1.0 where instability might arise. Furthermore, our ESS computation shows that we retain substantial information in our dataset.
} 
difference between the joint-distributions of Blacks and White arrestees on all observable case characteristics is less than $0.20 .^{25}$

-Table I about here-

The improvement in comparability across groups is even more apparent when demonstrated graphically. Figure III shows the trends in one current case characteristic and one criminal history characteristic before and after weighting. Before weighting, Blacks are substantially more likely to have a drug felony on their current case and are also more likely to have a prior custody event for a violent offense. However, when the samples are weighted as described above, the groups appear much more similar along both characteristics. Other characteristics included in the models experience similar reductions in differences across race (not shown).

$<$ Figure III about here>

A critical question being addressed in this paper is whether Proposition 36 reduced racial (Black-White) differences in commitments to prison. The top panel of Figure IV takes a simple look at dispositions to prison for Proposition 36 eligible offenses by quarter and shows the rates for Blacks and Whites in our sample. The un-weighted graph confirms that Blacks in our sample are more likely to receive a prison disposition than Whites. This difference is reduced dramatically in the weighted graph, which compares Blacks to our reweighted sample of Whites.

In both graphs, there are clear downward trends in the rate of prison dispositions for Blacks and Whites. We would expect a downward shift with Proposition 36, but this decline appears to begin earlier with state funding for drug courts in urban and more racially diverse counties like

\footnotetext{
${ }^{25}$ Rosenbaum (2010) suggests a standardized difference less than 0.20 should be considered a reasonably small effect size difference. We also examined the from effect size differences from Kolmogorov-Smirnov equality-ofdistributions test and found that they too were all less than 0.20 , indicating that our balance is not affected by choosing the mean as the indicator of comparability across groups.
} 
Alameda and Los Angeles. It is unclear from the graphs whether Proposition 36, which reduced judicial discretion regarding who might participate in diversion to drug treatment, had any effect in reducing Black-White disparities in prison commitments for drug offenses once drug courts became actively funded. $^{26}$

$<$ Figure IV about here>

The bottom panel of Figure IV shows diversion to treatment before and after Proposition 36 in the un-weighted and weighted samples. In the un-weighted graph, Blacks are less likely to receive diversion to treatment throughout the period though there is perhaps a narrowing over time. Weighting the sample does not reduce the differences between racial groups nearly as strongly as it did for prison.

While the graphs are useful in documenting raw difference and demonstrating the effect of reweighting, a regression framework is better suited to determining whether Proposition 36 influenced prison and diversion and whether it did so differentially for Blacks over Whites. Table II presents the unadjusted logistic regression comparisons of Blacks to Whites (Column 1), the results after weighting on the propensity score (Column 2), and the difference-in-difference estimates (Column 3).

The unweighted comparison in Column 1 shows that Blacks fare less favorably than Whites in receiving prison dispositions by a factor of 2.11. This coefficient is substantial in magnitude. Interpreted from the expected mean probability of prison, this suggests that Blacks have an average probability of being assigned to prison of 0.068 compared to only 0.034 for Whites. Column 2 shows that the likelihood of prison remains significantly larger for Blacks compared similarly-situated Whites even after adjusting on the propensity scores, but the

\footnotetext{
${ }^{26}$ It is worth noting that these trends are based on actual arrest charges to guard against the potential problem of prosecutors downgrading charges after arrest and contaminating the potential pool of eligible court dispositions.
} 
magnitude of the disparity shrinks substantially. The odds-ratio suggests that Blacks are now $17 \%$ more likely to be sentenced to prison after weighting on the vector of demographics, current arrest characteristics and criminal history characteristics. The expected probability of being assigned to prison for the average White arrestees that are similarly situated to the average Black arrestees increases to 0.059 .

A drawback of propensity score methods is that does not allow us to examine directly which variables are closing the gap between Blacks and Whites. But we can assess this indirectly by comparing how much the gap closes when we reweight the sample using a more limited number of variables. The odds-ratio when we reweight using only demographics and location remain largely unchanged from the unadjusted odds-ration $(\mathrm{OR}=2.29 * * *)$. If we also consider current arrest characteristics, but continue to exclude criminal history, Blacks remain nearly twice as likely to be sentenced to prison $\left(\mathrm{OR}=1.83^{* * *}\right)$. The take-away is that the addition of criminal history characteristics does the lion's share of reducing observed disparities in commitments to prison.

The difference-in-difference model in Column 3 shows that Proposition 36 reduced the likelihood of prison for all drug offenders as intended. The interaction effect is insignificant suggesting that the reduction does not appear to be concentrated among Blacks; given issues with respect to interpreting the interaction in non-linear models, we assessed significance by comparing the Proposition 36 effect from models estimated for Blacks and Whites separately $(\mathrm{z}=0.14)(\mathrm{Clogg}$, et al. 1995). But the direct effect of race (over the whole period) remains similar in magnitude and the gap in expected probabilities of prison narrows, as Whites now have 0.044 of prison compared to 0.050 among Blacks. 
The bottom panel of Table II presents the results for drug treatment dispositions. Blacks are significantly less likely than Whites to receive drug treatment dispositions with an odds ratio of 0.57 . That difference persists even after weighting by the propensity score. The average probability of a drug treatment disposition is 0.041 for a Black arrestee compared to 0.071 for an average White arrestee. The average probability of drug treatment barely changes after adjusting on the propensity score. However, the results in Column 3 show that the difference-indifference estimator is marginally statistically significant, suggesting that Blacks received a $19 \%$ relative increase (pre-post) from Proposition 36 in the odds of drug treatment compared to similarly-situated White arrestees $(\mathrm{z}=1.75+)$, which is reflected in the marginal shift upward in the probability of drug treatment for Blacks and shift downward for Whites. These findings suggest that California's Proposition 36 may have produced some marginal benefit in increasing the probability of dispositions to drug treatment for Black even compared to Whites who were similarly-situated on current arrest and criminal histories. However, the overall gap in the average expected probability of drug treatment remains substantial across groups, with 0.068 for Whites and 0.043 for Blacks.

-Table II about here-

\section{Sensitivity Analyses}

One concern we have is whether the effects noted above were truly due to the adoption of Proposition 36, or if they were part of the broader secular trend that was occurring with the expansion of drug courts. As noted previously, drug courts and related programs were ushered into California prior to Proposition 36 in various counties. Although our propensity score model controls for county and time period, it is possible that there were larger secular trends that we are not observing. In Table III, we compare the results of our main difference-in-difference estimate 
from Table II for the full sample period (1995 through 2005) to a similar estimate calculated only for those arrests between January 1999 and December 2003, which reflects a narrower 18-month period before and after the implementation of Proposition 36, largely capturing the period in which drug courts were being financially supported by the California state legislature. This shorter period allows us to consider whether Proposition 36 had an incremental effect on BlackWhite disparities above and beyond the expansion of drug courts in California. However, it is important to keep in mind that by focusing on a shorter period, we reduce the sample significantly. The baseline sample (ignoring the effective sample size calculation from the weights) shrinks from 96,507 to 48,564 by removing years 1995-1998 and 2004-2005. The smaller sample will influence our ability to identify good matches for comparison and reduce statistical power.

Looking at the prison results for the difference-in-difference model in the second column of Table III, we find that the racial disparity for prison is even smaller in this sample and is no longer statistically significant (odds ratio $=1.05$ ). Importantly, however, Proposition 36 is still associated with a reduction in the likelihood of being committed to prison above and beyond what was occurring with just with the implementation of drug courts. As expected, given that that we are focusing on a period where alternatives to incarceration have already increased, the effect is smaller than before and only significant at the $10 \%$ level (odds ratio $=0.722$ ). As before, there is no evidence of differential effects of Proposition 36 on prison for Blacks versus Whites ( $\mathrm{z}=0.064)$.

In terms of diversion to drug treatment, the findings are also materially the same across samples. Blacks remain significantly less likely than similarly-situated Whites to receive drug treatment (odds ratio $=0.515$ ). Likewise, the overall effect of Proposition 36 remains 
insignificant. Here again, however, there is suggestive evidence of increased access to treatment for Blacks relative to Whites after Proposition 36 (odds ratio=1.268) although this difference is no longer statistically significant at conventional levels $(\mathrm{z}=1.23)$. This may be due to reduced power in the much smaller sample ${ }^{27}$ and perhaps the fact that the effect of Proposition 36's is less pronounced when compared to this narrower time period.

A second way to look at this same issue is to consider separately those counties which did not already have a substantial share of their treatment admissions devoted to criminal justice referrals in the pre-Proposition 36 period. Counties with low shares are less likely to have participated less in the DCPA, CDCI and other drug court programs and so should experience a larger "shock" due to Proposition 36. We selected Amador, Contra Costa, Fresno, Los Angeles, Orange, Sacramento, San Benito, San Francisco and San Joaquin because the share of treatment admissions due to criminal justice referrals were consistently below the $25^{\text {th }}$ percentile for the period from 1998 to 2000 .

Similar to the shorter time-period in the statewide sample, race is no longer significant in the weighted sample when the outcome is prison. Not surprisingly, Proposition 36 had a somewhat larger effect on reducing prison dispositions in counties that had low criminal justice referral rates in the pre-Proposition 36 period than observed for the full sample. Again there is no evidence of a differential effect by race $(\mathrm{z}=1.35)$. Race, however, continues to be highly significant when the outcome is diversion. Similar to our full sample, there is no effect of Proposition 36 on diversions overall. The interaction effect, as we saw in the shortened time period, shows a larger but not quite statistically significant effect for Blacks relative to Whites $(\mathrm{OR}=1.26 ; \mathrm{z}=1.60)$

\footnotetext{
${ }^{27}$ With a reduction in effective sample size our power to detect an effect drops from 0.98 to 0.36 , assuming that the expected probability of prison was 0.044 and moves to 0.0485 for the White comparison group.
} 
A final concern is that we could consider incarceration more broadly rather than focusing solely on prison. While Proposition 36 targeted prison specifically, it may be important to consider how jail was affected. This also allows us to examine an outcome that does not suffer from the low prevalence rates observed for prison and diversion. Jail is fairly common in our sample with approximately one in four arrests resulting in a jail disposition.

In the unweighted sample, Blacks are significantly less likely to receive a jail disposition than Whites (odds ratio $=0.808^{* *}$ ). No significant differences remain once the sample is weighted with the propensity score using the full set of covariates. Similar to prison, there is a significant reduction in the use of jail coincident with the implementation of Proposition 36 $(\mathrm{OR}=0.700 * *)$. The interaction effect suggests the reduction in jail is somewhat larger for Whites $\left(\mathrm{z}=2.03^{*}\right)$. These results are similar to what we observed with prison and provide little evidence that jail substituted for prison for Blacks after Proposition 36.

\section{Conclusions}

We set out to study the racial disparities in prison and drug treatment dispositions in criminal courts in California. California is the bellwether state for prison overcrowding, some of this brought on by the drug prohibition. California also represents a unique environment in which to examine these associations because of its large demographic and regional diversity, the availability of detailed administrative data representing a census of individuals arrested and processed through the California court system, and the adoption of Proposition 36 which promotes treatment of drug offenders in lieu of prison. Because the law applies to the entire state, this study is able to reduce the amount of statistical noise typically involved in studies that examines differences between states over time. And, by including the temporal impact of Proposition 36 on the processing of drug offenders, we are able improve our ability to identify 
racial disparities in dispositions by detecting whether there are differential shifts for Whites relative to Blacks.

A common concern is that the drug prohibition unduly affects racial minorities. Our results suggest only partial support for this position. Our unadjusted data confirm large differences between Blacks and Whites in outcomes related to prison and drug diversion. However, when we compare Blacks to Whites who are similarly-situated in terms of their current arrest and criminal history characteristics, the difference in the likelihood of prison shrinks substantially. Criminal history characteristics appear to explain most of the racial disparities in prison dispositions. Proposition 36 was successful in reducing Prison dispositions overall, but there is no evidence of a differential effect for Black male arrestees compared to similarlysituated Whites. The outcomes for diversion to drug treatment, however, indicate more favorable positions for Whites relative to Blacks. The analysis suggests that Proposition 36 may have had some effect on reducing the disparity in diversion, with Blacks experiencing a modest increase in the probability of receiving a treatment disposition compared to similarly-situated Whites, although the results are not statistically significant at traditional (0.05) levels.

Our supplemental analyses of the shorter time period suggest that Proposition 36 did little to reduce commitments to prison beyond the downward trend that began with the increase in statewide funding for drug courts among this population. This may be due to the fact that the Blacks in our sample (whom the Whites are matched to) are drawn largely from a few big counties that quickly adopted and expanded drug court programs. Thus, because of the limited geographic variability in the location of Blacks in California and the fact that they tend to be highly concentrated in areas that adopted drug courts early, it is possible that our estimates under-estimate the incremental effect that a statewide policy would have above and beyond what 
drug courts could do alone. What is absolutely clear is that diversion within the state of California, whether considered in terms of drug courts or Proposition 36, did in fact reduce commitments to prison for both Blacks and Whites. Thus, it is effective at reducing the burden on prisons. The extent to which the diversion policy differentially helped Blacks vis-à-vis Whites remains unclear, as Blacks were no less likely to get prison once we account for Proposition 36 and show at best modest improvements with respect to diversion to drug treatment.

Reducing racial disparities in criminal dispositions to prison and drug treatment is important, as these disparities are likely to reinforce current imbalances in the criminal justice system. There is evidence that offenders referred to treatment may have lower risks for future recidivism and greater access to health services (Spohn and Holleran, 2002; Iguchi et al., 2005; Golembeski and Fullilove, 2005). The results are also important from a public health and economic perspective because of the positive gains associated with drug treatment in general. To the extent that laws like Proposition 36 make diversion to treatment a mandatory option in lieu of prison and improves access to treatment for Blacks, such policies may help reduce some racial disparities and potentially reduce long-term health disparities brought on by drug-related behaviors. 


\section{Author Affiliations}

Nancy Nicosia, Ph.D.

Senior Economist

RAND Corporation

20 Park Plaza, Suite 920

Boston, MA 02116

Phone: 617-338-2059 x 8627

Email: nicosia@ rand.org

John M. MacDonald, Ph.D.

Associate Professor

Chair, Department of Criminology

Director, Jerry Lee Center of Criminology

3718 McNeil, Suite 483

University of Pennsylvania

Philadelphia, PA 19104

Phone: 215-746-3623

Email: johnmm@sas.upenn.edu

Rosalie Liccardo Pacula, Ph.D.

Co-Director RAND Drug Policy Research Center

Acting Director, RAND Health Economics, Finance and Organization Program

Senior Economist, RAND Corporation

Professor, Pardee RAND Graduate School

Faculty Research Fellow, NBER

1776 Main St., P.O. Box 2138

Santa Monica, CA 90407-2138 USA

Phone: 310-393-0411 ext 6494

Email: pacula@rand.org 


\section{References}

Angrist, J. D., G. W. Imbens, and D. B. Rubin. (1996). Identification of causal effects using instrumental variables. Journal of the American Statistical Association 91:444-55.

Beckett, K., Nyrop K., and L. Peingst. (2006). Race, drugs and policing: Understanding disparities in drug delivery arrests. Criminology 44(1): 105-137.

Blumstein, A. (1993). Racial disproportionality of U.S. prison populations revisited. University of Colorado Law Review 64: 743-760.

Blumstein, A., and J. Wallman. (2000). The Crime Drop in America. New York: Cambridge University Press

Blumstein, A. (2002). Prisons: A policy challenge. In J. Q. Wilson \& J. Petersilia (Eds.) (pp. 451-482), Crime: Public policies for crime control. Oakland, CA: ICS Press.

Blumstein, A. (2011a). Approaches to reducing both imprisonment and crime. Criminology \& Public Policy 10(1): 93-101.

Blumstein, A. (2011b). Bringing down the U.S. prison population. The Prison Journal Supplement 91(3): 12S-26S.

Blumstein, A., and A. J. Beck. (2005). Reentry as a transient state between liberty and recommitment. In J. Travis \& C. Visher (Eds.) (pp. 50-79), Prisoner Reentry and Crime in America. Cambridge, UK: Cambridge University Press.

Bureau of Justice Statistics, online at: http://bjs.ojp.usdoj.gov/content/glance/tables/corr2tab.cfm

Bushway, S. D., and A. M. Piehl. (2001). Judging judicial discretion: Legal factors and racial discrimination in sentencing. Law \& Society Review 35(4): 733-764.

Busso, M., DiNardo, J., and J. McCrary. (2011). New Evidence on the Finite Sample Properties of Propensity Score Reweighting and Matching Estimators. Working Paper.

California Department of Alcohol and Drug Programs (2004). Comprehensive Drug Court Implementation Act of 1999: Interim Report to the Legislature. Sacramento, California.

California Department of Justice (2006). Crime in California 2005. Criminal Justice Statistics Center, Sacramento California.

Caulkins, J.P., Rydell, P., Schwabe, W.L., and J. Chiesa. (1997). Mandatory Minimum Drug Sentences: Throwing Away the Key or the Taxpayers' Money? RAND Research Monograph MR827-DPRC, Santa Monica, California. ISBN: 0-8330-2453-1. 
Clogg, C., Petkova, E., \& Haritou, A. (1995). Statistical methods for comparing the regression coefficients between models. American Journal of Sociology, 100, 1261-1293.

Drug Court Partnership (2002). Drug Court Partnership Act of 1998, Chapter 1007, Statutes of 1998: Final Report. The California Department of Alcohol and Drug Programs and the Judicial Council of California, Administrative Office of the Courts.

Engen, R. L., Gainey, R., Crutchfield, R.D., and J. G. Weis. (2003). Discretion and disparity under sentencing guidelines: The role of departures and structured sentencing alternatives. Criminology 41(1):99-130.

Ettner, S.L., Huang, D., Evans, E., Ash, D.R., Hardy, M., Jourabchi, M., and Y. Hser (2006). Benefit-cost in the California treatment outcome project: Does substance abuse treatment "pay for itself?" Health Services Research 41 (1): 192-213.

Golembeski, C., and R. Fullilove (2005). Criminal (In)Justice in the City and Its Associated Health Consequences. American Journal of Public Health 95:1701-1706.

Gottfredson, D.C., Najaka, S.S., and B. W. Kearley. (2003). Effectiveness of drug treatment courts: Evidence from a randomized clinical trial. Criminology and Public Policy 2: 171-196.

Greenwood, P., Model, K., Rydell, C.P., and J. Chiesa. (1998). Diverting Children from a Life of Crime. Santa Monica, CA: RAND Corporation.

Harris, C., Steffensmeier, D., Ulmer, J.T., and N. Painter-Davis. (2009). Are blacks and Hispanics disproportionately incarcerated relative to their arrests? Racial and ethnic disproportionality between arrest and incarceration. Race and Social Problems 1(4):187-199.

Harrison, P. M. and A.J. Beck. (2005). Prisoners in 2004. Bureau of Justice Statistics Bulletin. Washington, DC: Bureau of Justice Statistics, U.S. Department of Justice, NCJ 210677.

Hawken, A., Anglin, M.D., and B. T. Conner. (2007). Evaluation of the Substance Abuse and Crime Prevention Act Final Report Final Report of the 2001-2006 SACPA Evaluation, also known as the 2005 Report. Prepared for the Department of Alcohol and Drug Programs California Health and Human Services Agency.

Hayes, Joseph M. (2012). Just the Facts. California's Changing Prison Population. San Francisco: CA, Public Policy Institute of California.

Heckman, J. and P. Todd. (2009). A Note on Adapting Propensity Score Matching and Selection Models to Choice Based Samples. Economic Journal 12(1): S230-S234.

Hirano, K. and G. Imbens. (2001). Estimation of causal effects using propensity score weighting: An application to data on right heart catheterization. Health Services and Outcomes Research Methodology 2, 259-278. 
Hirano, K., Imbens, G., and G. Ridder. (2003). Efficient estimation of average treatment effects using propensity score. Econometrica 71: 1161-1189.

Hser Y.I., Teruya C., Brown A.H., Huang D., Evans E., and M.D. Anglin (2007). Impact of California's Proposition 36 on the drug treatment system: treatment capacity and displacement. American Journal of Public Health 97(1):104-9.

Huber, P.J. (1967). "The Behavior of Maximum Likelihood Estimates Under Nonstandard Conditions,' in Proceedings of the Fifth Berkeley Symposium on Mathematical Statistics and Probability, Volume I, Berkeley: University of California Press, pp. 221-233.

Ho DE, Imai K, King G, and E.A. Stuart. (2007). Matching as nonparametric preprocessing for reducing model dependence in parametric causal inference. Political Analysis 15:199-236.

Iguchi M.Y., Bell J., Ramchand R., and T. Fain. (2005). How criminal justice system racial disparities may translate into health disparities. Journal of Health Care for the Poor and Underserved 16(4): 48-56.

Imbens, G. and D. Rubin. (2008). Causal Inference in Statistics, and in the Social and Biomedical Sciences. Cambridge Univ. Press, New York.

Jacobs, D. and J. T. Carmichael. (2001). The politics of punishment across time and space: A pooled time-series analysis of imprisonment rates. Social Forces 80:61-89.

Kang, J. D. Y. and J.L. Schafer. (2007). Demystifying Double Robustness: A Comparison of Alternative Strategies for Estimating a Population Mean from Incomplete Data. Statistical Science 22(4):523-539.

Keen, B. and D. Jacobs. (2009). Racial Threat, Partisan Politics, and Racial Disparities in Prison Admissions: A Panel Analysis. Criminology 47: 209-238.

Klepper, S., Nagin, D. S., and L. Tierney. (1983). Discrimination in the Criminal Justice System: A Critical Appraisal of the Literature. In A. Blumstein, J. Cohen, S. Martin, and M. Tonry (eds.), Research on Sentencing: The Search For Reform (Vol. 2, pp. 55-128). Washington, DC: National Academy Press.

Klein, S., Petersilia J., and S. Turner. (1990). Race and imprisonment decisions in California. Science 247: 812-816.

Klein, S. P., Berk, R.A., and L. J. Hickman. (2005). Race and the Decision to Seek the Death Penalty in Federal Cases. Santa Monica, CA: RAND Corporation.

Kramer, J. and D. Steffensmeier. (1993). Race and imprisonment decisions. Sociological Quarterly 34 (2): 357-76. 
Langan, P. (1985). Racism on trial: New evidence to explain the racial compositions of prisons in the United States. Journal of Criminal Law and Criminology 76: 666-683.

Langan, P. (2001). Effect of choice of measure on the size of a racial disparity. Journal of Quantitative Criminology 17: 273-290.

Lee, B. K., Lessler, J., and E.A. Stuart. (2009). Improving propensity score weighting using machine learning. Statistics in Medicine 29(3):337-346.

McCaffrey, D. F., Ridgeway, G., and A. R. Morral. (2004). Propensity score estimation with boosted regression for evaluation adolescent substance abuse treatment. Psychological Methods 9: 403-425.

Mitchell, O. (2005). A meta-analysis of race and sentencing research: Explaining the inconsistencies. Journal of Quantitative Criminology 21: 439-466.

Morgan, S. L. and C. Winship. (2007). Counterfactuals and Causal Inference: Methods and Principles for Social Research. Cambridge Univ. Press, Cambridge.

Mustard, D. (2001). Racial, ethnic and gender disparities in sentencing: Evidence from the U.S. federal courts. Journal of Law \& Economics 44:285-314.

National Research Council. (2004). Measuring Racial Discrimination. Washington, DC: National Academies Press.

Paternoster, R., and R. Brame. (2008). Reassessing Race Disparities in Maryland Capital Cases. Criminology 46: 971-1008.

Pollack, H., Reuter, R., and E. Sevigny. (2011). If drug treatment works so well, why are so many drug users in prison? In (Eds. P. J. Cook, J. Ludwig, and J. McCrary) (pp. 125-160). Controlling Crime: Strategies and Tradeoff. NBER. University of Chicago Press, Chicago, IL.

Prendergast, M. L., Hall, E. A., Wexler, H. K., Melnick, G., and Y. Cao. (2004). “Amity Prisonbased Therapeutic Community: Five-year Outcomes. Prison Journal 84(1): 36-60.

Ramchand, R., Pacula R. L., and M. Iguchi. (2006). Racial differences in marijuana-users' risk of arrest in the United States. Drug and Alcohol Dependence 84(3): 264-72.

Raphael, S., and M.A. Stoll. (2009). "Why are so many Americans in prison?" in in Steven Raphael and Michael Stoll (eds.) Do Prisons Make Us Safer? The Benefits and Costs of the Prison Boom Russell Sage Foundation, New York, 2009.

Reuter, P., Hirschfield, P., and C. Davies. (2001). Assessing the Crack-Down on Marijuana in Maryland. Baltimore, MD: The Abell Foundation. 
Ridgeway, G., and J. M. MacDonald. (2009). "Doubly Robust Internal Benchmarking and False Discovery Rates for Detecting Racial Bias in Police Stops." Journal of the American Statistical Association_104, No. 486.

Ridgeway, G. and D.F. McCaffrey (2007). “Comment on 'Demystifying Double Robustness: A Comparison of Alternative Strategies for Estimating a Population Mean from Incomplete Data' by Kang and Schafer," Statistical Science 22(4):540-543.

Riley J. K. (1997). Crack, Powder Cocaine, and Heroin: Purchase and Use Patterns in Six Cities. Washington DC: U.S. Department of Justice, National Institute of Justice and Office of National Drug Control Policy.

Riley, J.K. et al. (2005). Just Cause or Just Because?: Prosecution and Plea-Bargaining Resulting in Prison Sentences on Low-level Drug Charges in California and Arizona. Santa Monica, CA: RAND Corporation.

Rosenbaum, P. (2010). Design of Observational Studies. Springer Series in Statistics, New York, Springer.

Rubin, D. B. (1974). "Estimating Causal Effects of Treatments in Randomized and Nonrandomized Studies.” Journal of Educational Psychology 66(5):688-701.

SAMHSA (2005). 1993-2003 treatment episode data set (TEDS) report of substance abuse treatment admissions. Office of Applied Studies. DASIS Series S-29, DHHS Publication No. (SMA) 05-4118.

Smith J.A., and P.E. Todd. (2005). Does matching overcome LaLonde's critique of nonexperimental estimators? Journal of Econometrics 125:305-353.

Spohn C., and R. Fornango (2002). U.S. Attorneys and Substantial Assistance Departures: Testing for Inter-prosecutor Disparity" Criminology 47: 813-846.

Spohn, C., and D. Holleran. (2002). "The Effect of Imprisonment on Recidivism Rates of Felony Offenders: A Focus on Drug Offenders." Criminology 40: 329-358.

Steffensmeier, D., and S. Demuth (2000). Ethnicity and sentencing outcomes in U.S. federal courts: Who is punished more harshly? American Sociological Review 65: 705-729.

Stuart EA. (2010). Matching methods for causal inference: A review and a look forward. Statistical Science 25:1-21.

Tibshirani, R. (1995), "Regression Selection and Shrinkage Via the Lasso." Journal of the Royal Statistical Society: Series B 57: 267-288.

Tonry, M. (1995). Malign neglect: Race, crime, and punishment in America, New York, NY: Oxford University Press. 
Turner, S., D. Longshore, S. Wenzel et al. (2002). A Decade of Drug Treatment Court Research. Substance Use and Misuse, 37, 12, 1489-14527.

Western, B. (2006). Punishment and Inequality in America. New York: Russell Sage Foundation.

Wintemute, G. J., Wright, M.A., Drake, C.M., and J.J. Beaumont. (2001). "Subsequent Criminal Activity Among Violent Misdemeanants Who Seek to Purchase Handguns: Risk Factors and Effectiveness of Denying Handgun Purchase." Journal of the American Medical Association 285(8):1019-1026.

Wooldridge, J. (2002). Econometric Analysis of Cross Section and Panel Data. Cambridge: MIT Press. 


\section{Table I}

\section{Comparison of Blacks to Whites after Balancing on Propensity Score}

\begin{tabular}{|c|c|c|c|c|}
\hline & Black & White & White & $d$ \\
\hline & & Unweighted & Weighted & \\
\hline Overall Effective Sample & $\mathrm{N}=25,618$ & $\mathrm{~N}=70,889$ & $\mathrm{ESS}=8,517$ & \\
\hline \multicolumn{5}{|l|}{ Pre-Proposition 36} \\
\hline Drug/Alcohol Felony & 0.777 & 0.59 & 0.743 & 0.05 \\
\hline Drug/Alcohol Misdemeanor & 0.454 & 0.769 & 0.53 & 0.12 \\
\hline Arrest Violent Felony & 0.03 & 0.023 & 0.024 & 0.028 \\
\hline Arrest Violent Misdemeanor & 0.014 & 0.012 & 0.012 & 0.021 \\
\hline Arrest Property Felony & 0.043 & 0.06 & 0.051 & 0.033 \\
\hline Arrest Property Misdemeanor & 0.019 & 0.025 & 0.022 & 0.016 \\
\hline Other Felony & 0.08 & 0.059 & 0.066 & 0.046 \\
\hline Other Misdemeanor & 0.176 & 0.193 & 0.163 & 0.027 \\
\hline Arrest Cycle & 10.954 & 6.09 & 9.449 & 0.148 \\
\hline Number Prior Arrests & 14.84 & 8.504 & 13.381 & 0.092 \\
\hline Juvenile Arrest Flag & 0.264 & 0.089 & 0.213 & 0.116 \\
\hline Prior Drug Alcohol Felony & 3.456 & 1.607 & 2.762 & 0.155 \\
\hline Prior Drug Alcohol Misd & 1.945 & 1.724 & 2.079 & 0.034 \\
\hline Violent Felony Priors & 1.663 & 0.517 & 1.351 & 0.126 \\
\hline Violent Misd Priors & 0.566 & 0.287 & 0.497 & 0.053 \\
\hline Property Felony Priors & 2.594 & 1.373 & 2.301 & 0.065 \\
\hline Property Misd Prior & 0.801 & 0.589 & 0.902 & 0.056 \\
\hline Other Felony Priors & 0.707 & 0.419 & 0.711 & 0.003 \\
\hline Other Misd Priors & 2.404 & 1.404 & 2.048 & 0.098 \\
\hline Weapons Felony Priors & 0.018 & 0.02 & 0.013 & 0.04 \\
\hline Sex Felony Priors & 0.001 & 0.001 & 0.001 & 0 \\
\hline Weapons Misd Priors & 0.007 & 0.013 & 0.008 & 0.007 \\
\hline Sex Misd Priors & 0.002 & 0.002 & 0.002 & 0.003 \\
\hline Prior Conviction & 0.81 & 0.655 & 0.784 & 0.067 \\
\hline
\end{tabular}




\begin{tabular}{|c|c|c|c|c|}
\hline & Black & White & White & $d$ \\
\hline & & Unweighted & Weighted & \\
\hline Prior Prison & 0.295 & 0.112 & 0.242 & 0.115 \\
\hline Prior Conviction Counts & 4.453 & 2.954 & 4.381 & 0.015 \\
\hline Prior Prison Counts & 0.696 & 0.265 & 0.57 & 0.094 \\
\hline Warrant & 0.206 & 0.144 & 0.185 & 0.053 \\
\hline Prob/Parole violations & 0.101 & 0.065 & 0.079 & 0.073 \\
\hline Prior Violent Felony Flag & 0.113 & 0.026 & 0.094 & 0.062 \\
\hline Prior Property Felony Flag & 0.154 & 0.079 & 0.142 & 0.034 \\
\hline Prior Drug Felony Flag & 0.219 & 0.086 & 0.171 & 0.116 \\
\hline Prior Other Felony Flag & 0.059 & 0.025 & 0.063 & 0.016 \\
\hline
\end{tabular}

\section{Post-Proposition 36}

Drug/Alcohol Felony

Drug/Alcohol Misdemeanor

$\begin{array}{llll}0.664 & 0.443 & 0.644 & 0.028 \\ 0.596 & 0.912 & 0.678 & 0.122 \\ 0.036 & 0.023 & 0.032 & 0.018 \\ 0.014 & 0.012 & 0.013 & 0.011 \\ 0.047 & 0.06 & 0.057 & 0.038 \\ 0.018 & 0.022 & 0.02 & 0.009 \\ 0.134 & 0.063 & 0.103 & 0.075 \\ 0.351 & 0.299 & 0.325 & 0.036\end{array}$

Other Misdemeanor

$13.155 \quad 6.976$

$10.749 \quad 0.197$

Arrest Cycle

19.934

10.905

16.982

0.141

Juvenile Arrest Flag

0.311

0.132

0.265

0.101

Prior Drug Alcohol Felony

4.199

1.626

3.159

0.185

Prior Drug Alcohol Misd

2.682

2.54

2.755

0.015

Violent Felony Priors

1.821

0.568

1.413

0.151

Violent Misd Priors

0.635

0.339

0.557

0.055

Property Felony Priors

2.656

1.26

2.259

0.082

Property Misd Prior

0.832

0.572

0.878

0.025

Other Felony Priors

$1.422 \quad 0.557$

1.067

0.151

Other Misd Priors

3.938

2.153

3.217

0.131 


$\begin{array}{lllll}\text { Weapons Felony Priors } & 0.020 & 0.016 & 0.017 & 0.019 \\ \text { Sex Felony Priors } & 0.001 & 0.001 & 0.002 & 0.011 \\ \text { Weapons Misd Priors } & 0.006 & 0.007 & 0.006 & 0 \\ \text { Sex Misd Priors } & 0.003 & 0.002 & 0.002 & 0.018 \\ \text { Prior Conviction } & 0.826 & 0.647 & 0.792 & 0.089 \\ \text { Prior Prison } & 0.297 & 0.107 & 0.237 & 0.131 \\ \text { Prior Conviction Counts } & 5.586 & 3.734 & 5.294 & 0.049 \\ \text { Prior Prison Counts } & 0.799 & 0.262 & 0.605 & 0.123 \\ \text { Warrant } & 0.314 & 0.193 & 0.294 & 0.042 \\ \text { Prob/Parole violations } & 0.041 & 0.027 & 0.032 & 0.045 \\ \text { Prior Violent Felony Flag } & 0.122 & 0.028 & 0.084 & 0.118 \\ \text { Prior Property Felony Flag } & 0.167 & 0.073 & 0.15 & 0.045 \\ \text { Prior Drug Felony Flag } & 0.232 & 0.09 & 0.167 & 0.153 \\ \text { Prior Other Felony Flag } & 0.066 & 0.027 & 0.055 & 0.041\end{array}$

Note - These models also include county, arrest-year, arrest-month, arrest-severity (minimum), arrest-severity (median), and age at time of arrest. The comparisons on these coefficients are not displayed due to space constraints.

ESS $=$ the number of weighted comparison observations needed to obtain an estimate equivalent to that taken from a simple random sample and offers an estimate of the number of white observations that are comparable to black observations.

$d=$ effect size difference of standardized means. 


\section{Table II}

\section{Black-White Disparities in Prison and Drug Treatment by Propensity Score}

\begin{tabular}{|c|c|c|c|}
\hline & 1 & 2 & 3 \\
\hline Prison & Unadjusted & $\begin{array}{c}\text { Propensity } \\
\text { Score Weighted }\end{array}$ & $\begin{array}{c}\text { Propensity } \\
\text { Score Weighted }\end{array}$ \\
\hline Race & $\begin{array}{c}2.108 * * \\
(.068)\end{array}$ & $\begin{array}{l}1.169^{*} \\
(.072)\end{array}$ & $\begin{array}{c}1.171+ \\
(.099)\end{array}$ \\
\hline Proposition 36 & & - & $\begin{array}{c}0.552 * * \\
(.061)\end{array}$ \\
\hline Proposition $36 *$ Race & & - & $\begin{array}{l}0.987 \\
(.121)\end{array}$ \\
\hline $\begin{array}{l}\text { Mean Probability } \\
\text { Black = } \\
\text { White = }\end{array}$ & $\begin{array}{l}.068 \\
.034\end{array}$ & $\begin{array}{l}.068 \\
.059\end{array}$ & $\begin{array}{l}.050 \\
.044\end{array}$ \\
\hline Drug Treatment & Unadjusted & $\begin{array}{c}\text { Propensity } \\
\text { Score Weighted }\end{array}$ & $\begin{array}{c}\text { Propensity } \\
\text { Score Weighted }\end{array}$ \\
\hline Race & $\begin{array}{c}0.565 * * \\
(.019)\end{array}$ & $\begin{array}{c}0.568 * * \\
(.029)\end{array}$ & $\begin{array}{c}0.518 * * \\
(.038)\end{array}$ \\
\hline Proposition 36 & & - & $\begin{array}{l}0.907 \\
(.073)\end{array}$ \\
\hline Proposition $36 *$ Race & & - & $\begin{array}{c}1.194+ \\
(.122)\end{array}$ \\
\hline Mean Probability & & & \\
\hline $\begin{array}{l}\text { Black = } \\
\text { White = }\end{array}$ & $\begin{array}{l}.041 \\
.071\end{array}$ & $\begin{array}{l}.041 \\
.071\end{array}$ & $\begin{array}{l}.043 \\
.067\end{array}$ \\
\hline $\mathrm{N}=$ & 96,507 & 34,135 & 34,135 \\
\hline
\end{tabular}

Note: Odds Ratios presented and standard errors in parentheses. Robust standard errors are used in the propensity score models to accommodate the weights. The sample size changes in the propensity score model due to the effective sample size of Whites equaling 8,517.

Unadjusted is the without propensity scores.

Results in Columns 1-3 are based on logits over the January 1995-December 2005 period. $+\mathrm{p}<.10 ; * \mathrm{p}<.05 ; * * \mathrm{p}<.01$ 


\section{Table III}

Black-White Disparities in Prison and Drug Treatment - Sensitivity Analyses

\begin{tabular}{|c|c|c|c|}
\hline & $\begin{array}{l}\text { 1995-2005 } \\
\text { Sample }\end{array}$ & $\begin{array}{c}1999-2003 \\
\text { Sample }\end{array}$ & $\begin{array}{c}\text { Low CJ Share } \\
\text { Sample } \\
\end{array}$ \\
\hline Prison & $\begin{array}{c}\text { Propensity Score } \\
\text { Weighted }\end{array}$ & $\begin{array}{c}\text { Propensity Score } \\
\text { Weighted }\end{array}$ & $\begin{array}{c}\text { Propensity Score } \\
\text { Weighted }\end{array}$ \\
\hline Race & $\begin{array}{l}1.171+ \\
(.099)\end{array}$ & $\begin{array}{c}1.050 \\
(0.156)\end{array}$ & $\begin{array}{c}1.102 \\
(0.123)\end{array}$ \\
\hline Proposition 36 & $\begin{array}{c}0.552 * * \\
(.061)\end{array}$ & $\begin{array}{l}0.723+ \\
(0.133)\end{array}$ & $\begin{array}{l}0.460 * * \\
(0.073)\end{array}$ \\
\hline Proposition $36 *$ Race & $\begin{array}{l}0.987 \\
(.121)\end{array}$ & $\begin{array}{c}1.009 \\
(0.200)\end{array}$ & $\begin{array}{c}1.111 \\
(0.190)\end{array}$ \\
\hline $\begin{array}{l}\text { Mean Probability } \\
\text { Black = } \\
\text { White = }\end{array}$ & $\begin{array}{l}.050 \\
.044\end{array}$ & $\begin{array}{l}.050 \\
.048\end{array}$ & $\begin{array}{l}.054 \\
.044\end{array}$ \\
\hline Drug Treatment & $\begin{array}{c}\text { Propensity Score } \\
\text { Weighted }\end{array}$ & $\begin{array}{c}\text { Propensity Score } \\
\text { Weighted }\end{array}$ & $\begin{array}{c}\text { Propensity Score } \\
\text { Weighted }\end{array}$ \\
\hline Race & $\begin{array}{c}0.518 * * \\
(.038)\end{array}$ & $\begin{array}{l}0.515 * * \\
(0.070)\end{array}$ & $\begin{array}{l}0.492 * * \\
(0.050)\end{array}$ \\
\hline Proposition 36 & $\begin{array}{l}0.907 \\
(.073)\end{array}$ & $\begin{array}{c}1.055 \\
(0.143)\end{array}$ & $\begin{array}{c}0.930 \\
(0.106)\end{array}$ \\
\hline Proposition $36 *$ Race & $\begin{array}{l}1.194+ \\
(.122)\end{array}$ & $\begin{array}{c}1.268 \\
(0.210)\end{array}$ & $\begin{array}{c}1.256 \\
(0.176)\end{array}$ \\
\hline $\begin{array}{l}\text { Mean Probability } \\
\text { Black = } \\
\text { White }=\end{array}$ & $\begin{array}{l}.043 \\
.067\end{array}$ & $\begin{array}{l}.042 \\
.063\end{array}$ & $\begin{array}{l}.048 \\
.076\end{array}$ \\
\hline $\mathrm{N}=$ & 34,135 & 16,828 & 18,651 \\
\hline
\end{tabular}

Note: Odds Ratios presented and standard errors in parentheses. Robust standard errors are used in the propensity score models to accommodate the weights. The sample size changes in the propensity score model due to the effective sample size of Whites equaling 8,517.

$+\mathrm{p}<.10 ; * \mathrm{p}<.05 ; * * \mathrm{p}<.01$ 


\section{Table IV}

Black-White Disparities in Jail by Propensity Score

\begin{tabular}{lccc}
\hline & 1 & 2 & 3 \\
\hline Jail & Unadjusted & $\begin{array}{c}\text { Propensity Score } \\
\text { Weighted }\end{array}$ & $\begin{array}{c}\text { Propensity Score } \\
\text { Weighted }\end{array}$ \\
\hline Race & $0.808^{* *}$ & 1.006 & 0.964 \\
& $(0.014)$ & $(0.027)$ & $(0.039)$ \\
Proposition 36 & & - & $0.700^{* *}$ \\
& & - & $(0.032)$ \\
Proposition 36* Race & & & 1.087 \\
& & & \\
\hline \multirow{2}{*}{ Mean Probability } & & $0.059)$ \\
Black = & 0.232 & 0.232 & \\
White = & 0.272 & 0.231 & 0.209 \\
$\mathrm{~N}=$ & 96,507 & 34,135 & 0.201 \\
\hline
\end{tabular}




\section{Figure I}

\section{Criminal Justice Treatment Admissions by Race (California Only)}

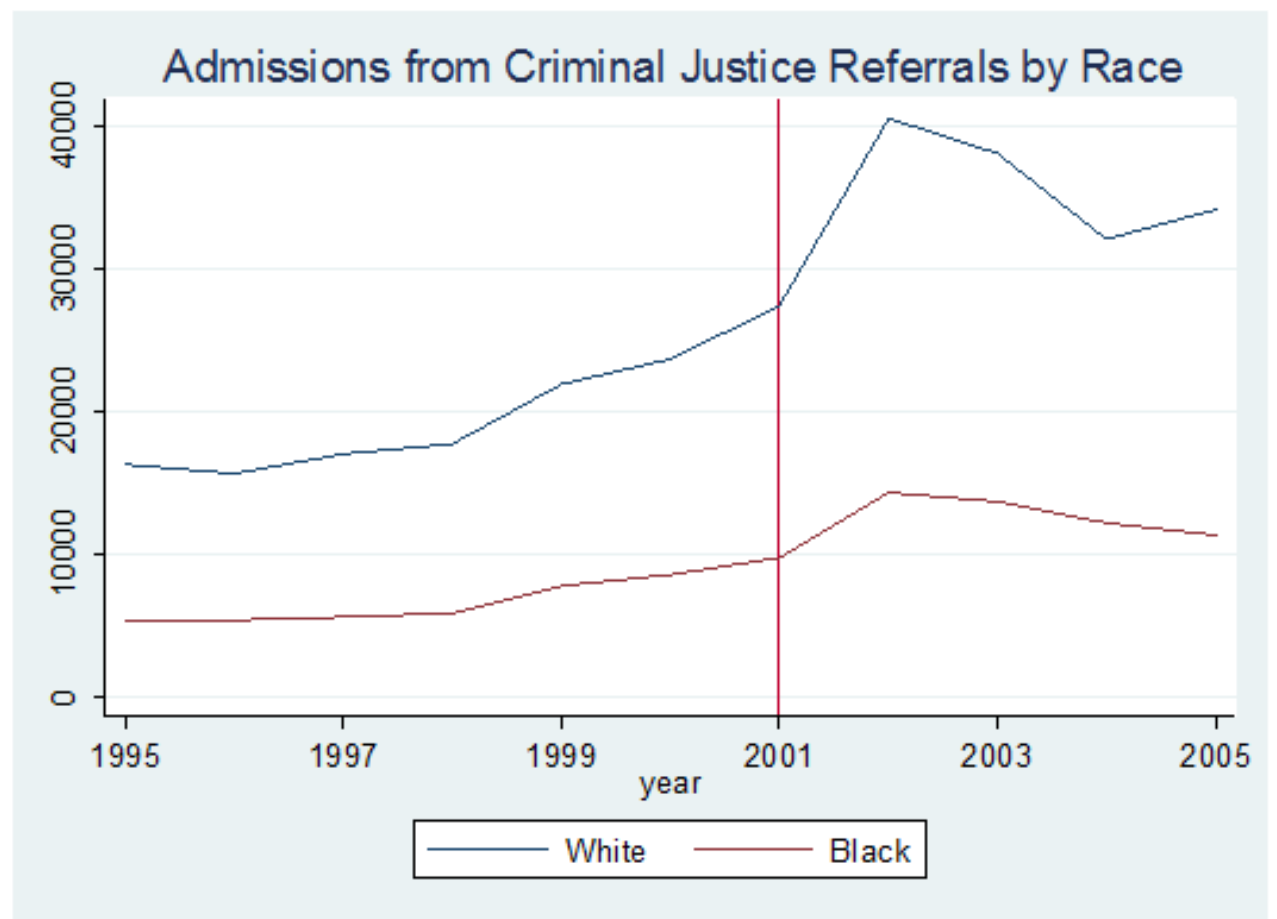

Source: Treatment Episode Data Set (TEDs) 
Figure II

New Prison Commitments among Drug Offenders by Race

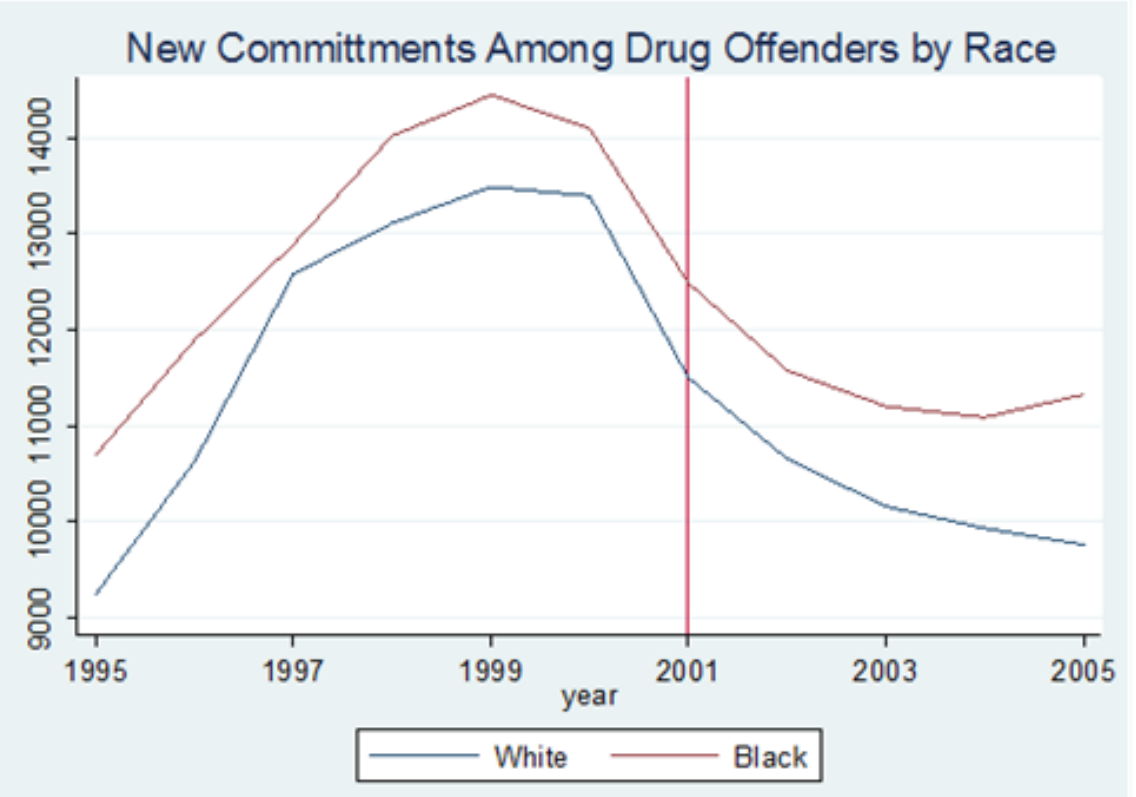

Source: California Department of Corrections and Rehabilitation data, 1995-2005 from Hayes (2012). 


\section{Figure III}

\section{Weighted and Unweighted Current Arrest and Criminal History Characteristics}
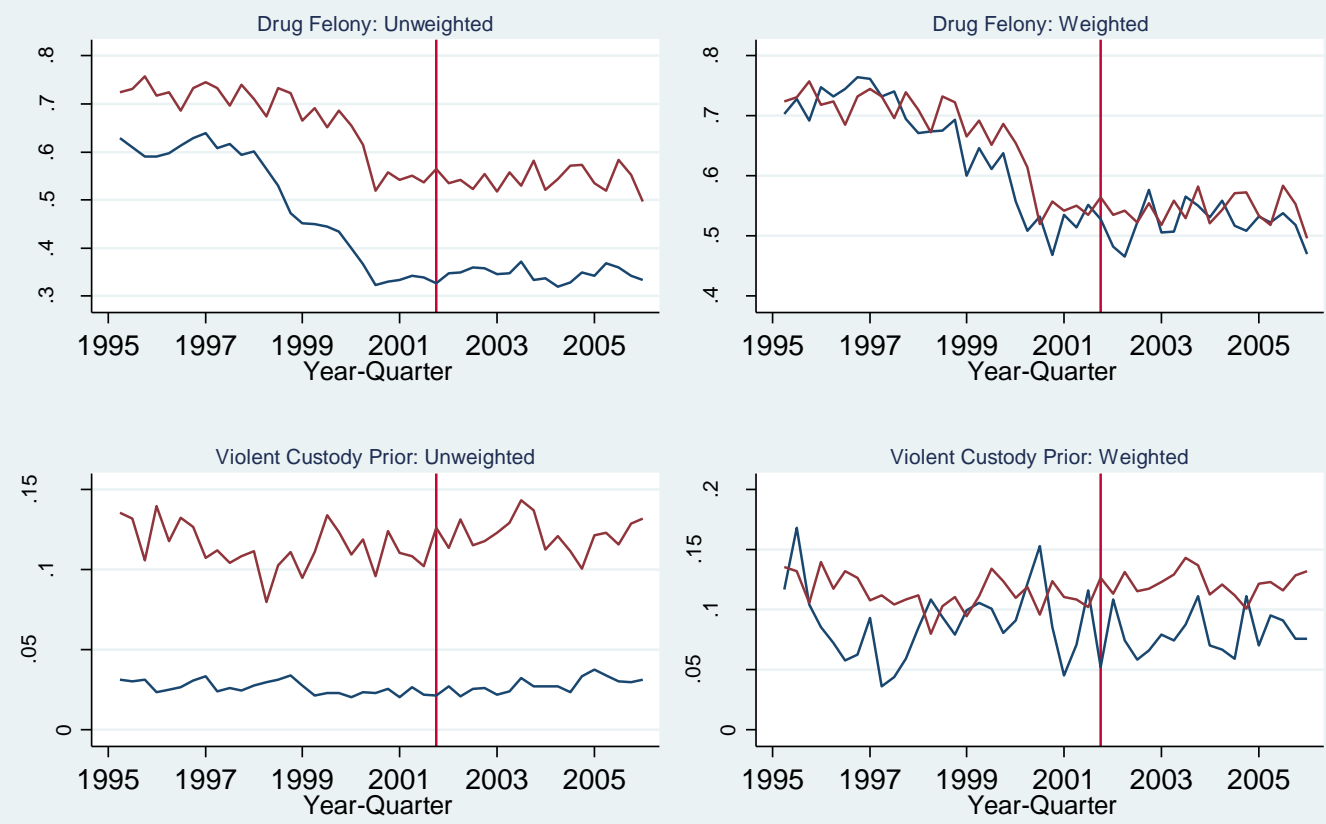


\section{Figure IV}

\section{Weighted and Unweighted Dispositions to Prison and Drug Treatment}
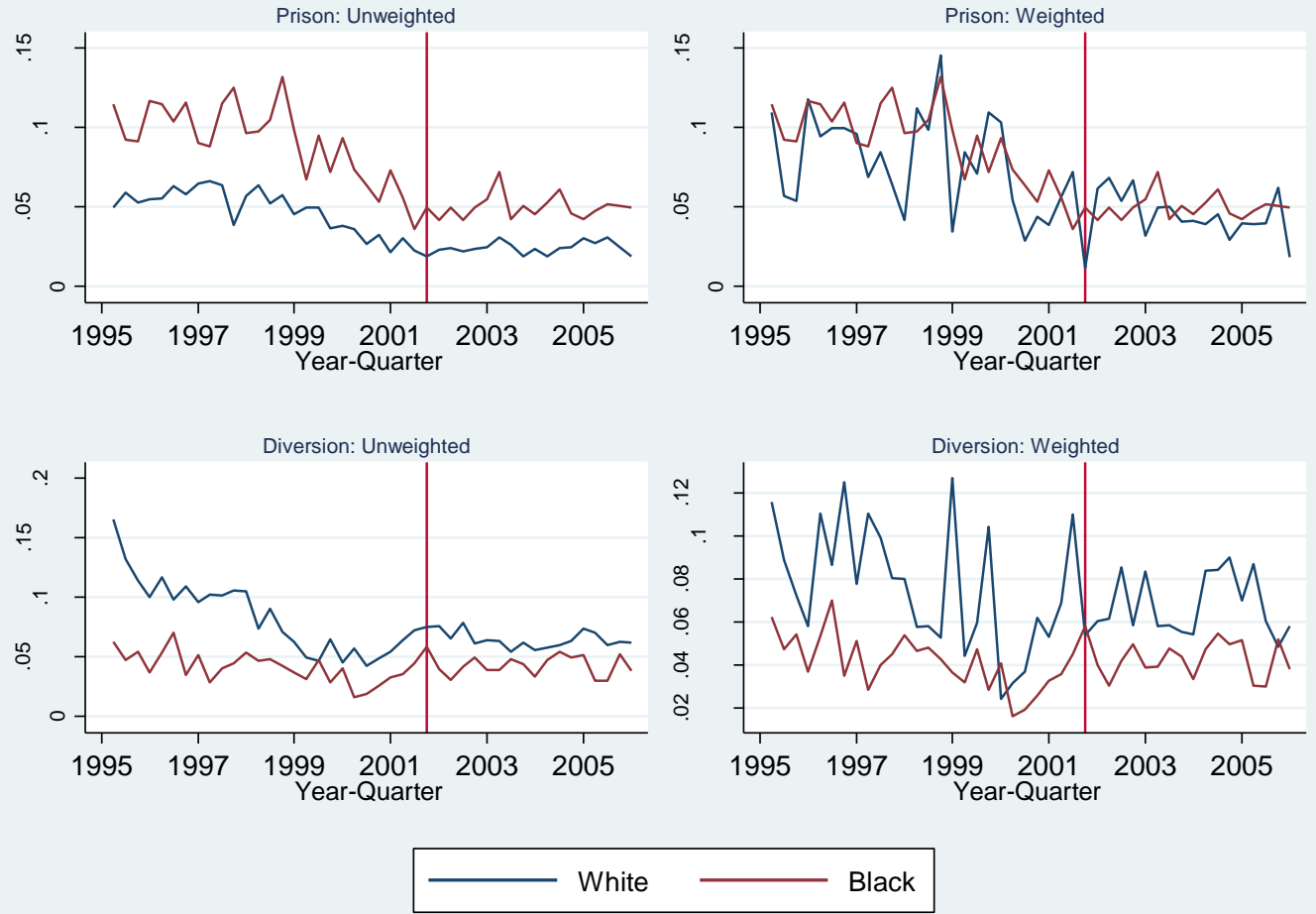